\title{
Study on Quality Education to Face the Demand-Oriented
}

\author{
Guohua Zhao, Weizhi Wang \\ Department of Mechanical Engineering, Hubei University of Automotive Technology, Shiyan, China \\ zgh-33333@163.com
}

\begin{abstract}
The basic goal of quality education is to cultivate the learners' ability of forming the spirit of science, professional knowledge, technical skills, and the sound personality. In order to meet the needs of the learners' personal development and the social development, the demand-oriented quality education is highly demanded. This article discusses the demand-oriented quality education and the related problems it brings forth.

Index Terms - Demand-oriented, Quality education

\section{Introduction}

Higher education needs reform, what is the goal of reform, and what is the power and direction of reform. In Order to adapt to the social development of effective demand, the direction and goals of higher education reform is to train the High-end laborer with the spirit of science, knowledge and technology, skills and healthy personality. Higher education needs to carry out the reform continuously on the teaching mode and content, for different regions and industries establishes the different style. Such a viewpoint is already widely recognized[1,3]. The momentum of reform comes from various aspects: the universities' own mission, the requirements of government departments, as well as the pressure from the community. These are the exterior pressures. But the real momentum of reform and development must come from their own development needs. Through the cognition and positioning of market, consciously practice quality education of demand guide.
\end{abstract}

\section{Management Objectives for the Overall Quality Education}

What is quality education? what is the management objective of quality education? To clarify this issue, first take a look at the specific meaning of quality education. As a pedagogy areas theory, this has not yet formed a unified definition. It's generally believed that quality education associated with the individual human development and social development, respect for individual students initiative, and focus on the development of individual potential and develop the sound personality characteristics[3,4]. In order to achieve management objectives of quality education, the following aspects need to give special attention.

First, each individual student is one of the future of social activities members, their development are always linked with the social development. So to leave community to discuss about the development of the individual is meaningless. This means that the fundamental goal of quality education is to adapt to the needs of the development of contemporary society, whether it is the idea of Oriental Humanities Education, or the Western theory of development of human values, are inseparable from education and social development to adapt to this rule. But does not mean not to pay attention to personal development, on the contrary, the formation of different individuals styles is the prerequisite for the development of society. In China, was stressed that the management objectives of quality education meet the needs of community a little more, emphasis on the development of individual students is not enough. Therefore, for the overall quality education reform should be particularly emphasized that the education is to student-centered, respect for students individual, develop a sound personality and creative spirit, and to adapt to the social development needs and to meet students' personality development of the organic combination.

Second, the quality education is the all-round development of education, can not only simply focus on scientific and cultural knowledge learning and training, the scientific spirit, sense of civic responsibility and a sound personality must be synchronized to the line. In today's colleges and universities, the training of scientific and cultural knowledge has formed the basic integrity of the system, mode, content and method, although rigid, but is relatively mature, the training of scientific spirit, civic responsibility and healthy personality education are in a fragmented situation. Impart knowledge and educate people is only a catchword, there is no clear quality objectives and operating specifications, in addition, the scientific spirit, sense of civic responsibility and integrity of character education is a systematic project, to some extent, the whole community have training responsibility, as colleges and universities, responsibility is more direct, more importantly.

Third, quality education is geared to the needs of all citizens, not just the selection of the elite crowd. Fair and equitable are the basic components of quality education, to recognize the individual differences of students' access to development opportunities, but must can have a positive meaning in a fair and equitable conditions. The education fair is fair society cornerstone. Previously reported that in the college, student organizations have some degree privilege and corruption, although not officially confirmed, maybe just an individual phenomenon, but should be taken seriously, if education itself is not fair, to achieve social equity and justice will not have the footstone.

Fifth, the quality education is to cultivate people's innovation capability as the core of education, the characteristics of the development of modern science and technology first, knowledge explosive growth, more and more disciplines, more and more refined classification. Second is between the disciplines of mutual integration, mutual 
penetration of disciplinary, differentiation and integration are exist at the same time, especially in the engineering field, integrated innovation has become an important form of innovation. Integrated innovation is inseparable from the team, this means when the quality education try to promote the individual freedom development, should also promote teamwork.

The sixth, previously discuss more emphasis on market attributes and individual attributes of the quality education, in fact, the quality education has social and political attributes, whether the Western or Eastern world, the country's overall interests are always the dominant education .Therefore, the quality education must be accord with the country's strategic interests. In China, the quality education must be accord with the modernization and the stability of the state long-term development strategy, the quality education must be accord with national economic development and meet the requirements of social modernization, from the needs of construction determine personnel training target system, quality education can train the personnel independent spirit and creatively engaged in the modernization construction of the state.

Seventh, the education should be facing the world, facing the future. Nowdays it is an inevitable choice for all countries to move into the international market to obtain ecomonic development opportunities at an unprecedented rate .The education face the world, face the future,, which means that education must stand on the height of an international perspective, note that the absorption of foreign advanced education theories, the world today, especially in developed countries, all put the training independent spirit and creative ability as the core of educational reform. For example, as early as 1996, the report submitted by the International Education Committee of the 21st century to UNESCO "Education Treasure which" emphasized that education should be to be organized around four basic learning, namely: Institute cognitive, learning to do, learn to live together, learn survival. Earlier, an educational research group published studies report" the potential of the United States - person" pointed out that the specifications for personnel training in the 21st century is: have a clear life goals and social responsibility; have to create awareness, and to the continuous acquisition of knowledge, and ability to constantly to overcome their own limitations. Japan's" Provisional Council for Education" pointed out that the educational goals at this stage is to cultivate talents with rich creativity, freedom, self-discipline and public spirit. France, Germany and England etc. country 's schools are also proposed to break old habits not simply to impart book knowledge of, the focus went to cultivate the students' ability and creativity so that they have the analysis, expression, understanding and application of capacity, in order to adapt to future social talent standard requirements[3].

Seen in terms of overall quality of education, the world has similar quality education values, therefore quality education reform should be widely absorb the advanced international educational philosophy and methods.

\section{Face to Demand-Oriented Quality Education}

To realize overall quality education from colleges and universities, the reform must be carried out. The most basic power come from their own development needs, come from market awareness and positioning, and come from the recognition and practice of demand-oriented concept.

Demand-driven is manufacturing industries, service industries generally adopted a management model, the core of this management model is to meet customers' needs as the highest work management objectives, or it is put as the company's purpose to meet customer needs for customers to create value. Comparison with the product-oriented and the technology-oriented, to meet customer demand-oriented management model is closer to the market, more easily gain market acceptance. Customer demand-oriented not only meet customers' current needs, must be given close attention to the customer's potential needs, generally potential customer demand means that it is creation and innovation of original product, not just passive response to customer needs. Customer demand-oriented create more and better products and services to guide and meet the needs of customers to obtain their own development. At the international level is widely recognized ISO 9001:2008"quality management system requirements", the first provision of the eight principles of quality management is customer focus, emphasizing: "organization dependent on the customer, organizations should understand customer current and future needs, meet customer requirements and strive to exceed customer expectations "[2].

The market function can optimize the resource allocation. Under the action of the market mechanism, the resources, capital, labor and other factors of production from areas of low efficiency will move to high efficiency in the field. Therefore, the market is the hotbed and source of innovation activities. With the continuous progress of science and technology and the unprecedented development of information, in mature markets inside, buyers and sellers is as the main body of market, they have freedom, equality choose right, just right this equal rights push forward the industry escalation of evolution, growing demand, market and improve the structure innovation. and thus create an endless stream new products and services, to some extent, the market just is an invisible but powerful hand.

The other hand, the higher education market, a variety of reasons, for example, enrollment system, the educational philosophy of the traditional dignity of the division, currently widely used rigid index evaluation and management system, etc. [5], The marketization degree will vary a lot. one of market players-students, only a limited to speak and to choose right .After the difficult entrance examination, some students will not be accepted, and the training program, teaching programs, internship programs, teaching quality and teaching materials, speak and to choose right is mainly in the educational institutions, students largely passive acceptance, which greatly limits supplier and demander both sides the competition effectiveness, through the competition to stimulate innovation activities are greatly reduced. As 
education market participants-social has relatively more right to speak, for example, some companies can justifiably claim recruitment to select only from a certain type university of graduates, the problem is their choice not help higher quality education improved. Between universities and enterprises, it is difficult to formation of benign competition, to some extent, university still exists in its own ivory tower. Similar to mode of teaching, a few years, ten years basically unchanged talent program, behind reality technology teaching materials and so on, can be as a proof.

Todays universities, though have the rich reserve of knowledge, due to lack of the use and management of these knowledge of market awareness, knowledge itself does not promote the development of University to produce a positive impact [4]. not have to feel pressure and challenges from the market, not have to the internal reform momentum, when education market to locate is difficult to reach agreement, the quality management of higher education is inevitably there will be like a blind man feeling an elephant [4].

Higher education reform solution should first update ideas, clearly develop demand-oriented quality education. As not fully market-oriented education market, specially need to self-reflect, pay attention to development needs of community and students, and continue to create new demand to meet the requirements of the overall quality education.

Higher education has a market property, but in the current market-oriented development is not mature enough stage, multi-participant is not in the compete stage of equality and freedom, self-examination is very important and urgent. No right to speak does not mean that there is no demand, does not mean there is no option. In the degree of internationalization of an increasingly high today, matriculate loss is already illustrate the problem.

\section{Conclusion}

The problems faced by the reform of higher education is multifaceted, first must clear the market for higher education awareness and positioning, reform index evaluation and management system, advocate academic management, knowledge management, develop demand-oriented quality education, so that the real market demand become the source of the power and innovation of the reform of higher education.

\section{References}

[1] Edward and Sallis, 2005 Total Quality Education, Shanghai: East China Normal University Press.

[2] Joseph M, Juran 2003 Juran Quality Manual. 5th ed, Beijing: Renmin University of China Press.

[3] Wang jianhua, "2009 Higher education quality management: the organization's perspective", Higher Education Exploration. 5 13-19

[4] Wang jianhua, "2009 Quality management of higher education: the Perspective of Knowledge", Fudan Education Forum. 7 46-51.

[5] Shi qiuheng and Wu xue, "2009 Analysis of UK higher education quality management system changes", Journal of Xiamen University. 193 106113. 